\title{
Comparing apples with oranges: The funfair of statistics
}

\author{
Ari A. Mennander, MD, PhD
}

\author{
From Tampere University Heart Hospital and Tampere University, Tampere, Finland. \\ Disclosures: Author has nothing to disclose with regard to commercial support. \\ Received for publication July 23, 2018; accepted for publication July 24, 2018; available ahead of print Sept 6, \\ 2018. \\ Address for reprints: Ari A. Mennander, MD, PhD, Tampere University Heart Hospital, SDSKIR, PL 2000, Tam- \\ pere, Finland (E-mail: ari.mennander@sydansairaala.fi). \\ J Thorac Cardiovasc Surg 2019;157:905-6 \\ $0022-5223 / \$ 36.00$ \\ Copyright (C 2018 by The American Association for Thoracic Surgery \\ https://doi.org/10.1016/j.jtcvs.2018.07.075
}

The $\mathrm{CHA}_{2} \mathrm{DS}_{2}$-VASc score estimates the risk of stroke in patients with atrial fibrillation. ${ }^{1,2}$ The $\mathrm{CHA}_{2} \mathrm{DS}_{2}$-VASc score accounts for congestive heart failure; hypertension; age of at least 75 years (doubled); diabetes mellitus; previous stroke, transient ischemic attack or thromboembolism (doubled); vascular disease; age 65 to 74 years; and sex category (female). Should the $\mathrm{CHA}_{2} \mathrm{DS}_{2}$-VASc score be considered as a categorical or a continuous factor, if the patients have an incremental increase in risk of death, stroke, or bleeding?

In the meticulous article by Kiviniemi and coworkers ${ }^{3}$ in this issue of the Journal, patients receiving a surgically implanted aortic valve bioprosthesis were categorized into 3 groups according to their $\mathrm{CHA}_{2} \mathrm{DS}_{2}$-VASc scores. The patient cohort represented 4 of the 5 University hospitals performing cardiac surgery in Finland, and a total of 714 patients were retrospectively analyzed. The strength of the study includes a complete follow-up of the patients discharged alive, reflecting information received from the hospitals and the national Finnish registry for causes and times of death for all patients. The study speculates that an additional surgical intervention, such as closure of the left atrial appendage, may be justified in patients with a high $\mathrm{CHA}_{2} \mathrm{DS}_{2}$-VASc score because of their increased stroke risk.

One must be proficient in statistical marvels to follow the methodology. The traditional Kaplan-Meier, the propensity score matching, and Cox proportional hazards analysis have all been replaced by a competing risks analysis. ${ }^{4}$ The idea is fascinating: one analyzes the outcome while considering that some of the stroke events may have been masked by premature death for some other reason.

Can mortality be considered an independent event without interaction from other events? Can mortality be evaluated as a competing-risk event for a recurrent stroke? Many risk factors increase the cumulative incidence of events that themselves may also affect mortality. Deatha literally dead end of any event-may or may not have occurred after a single or a multitude of risk factors or events. Death may occur after a strokelike insult; the patient

\section{References}

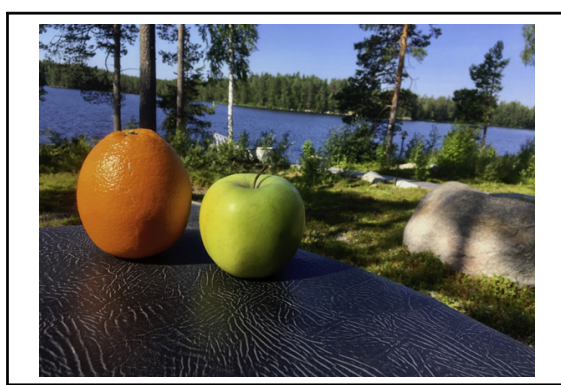

The combination of demographic parameters builds the risk profile of each patient.

\section{Central Message}

Patients either die or not; they either receive treatment or not-but the patients gather an incremental increase in risks of death, stroke, and bleeding.

See Article page 896.

may die of bleeding, frailty, or anything else and all, several, some, or none of these events may have occurred before death. There is the possibility of combining several recurrent events together, but then again, which events are to be combined to represent mortality as a cumulative outcome? If the differences between the patients with different $\mathrm{CHA}_{2} \mathrm{DS}_{2}$-VASc scores is not detected without performing a competing risk analysis, the practical use of the scoring may be of limited value. ${ }^{2}$

The study confirms that the sick patient deserves close attention postoperatively. The $\mathrm{CHA}_{2} \mathrm{DS}_{2}$-VASc score was not investigated to determine which patients would benefit from additional surgical intervention. The Finnish patients are all anticoagulated for 3 months after receiving a bioprosthesis, anticoagulation is closely monitored, and it is frequently continued thereafter even with a $\mathrm{CHA}_{2} \mathrm{DS}_{2}$ VASc score less than 2. ${ }^{5}$ As shown by Kiviniemi and coworkers, ${ }^{3}$ atrial fibrillation alone either before or after surgery did not have an impact on poor outcome. In addition, additional surgical interventions, such as left atrial closure and the maze procedure, are in themselves additional competing factors.

1. Orvin K, Levi A, Landes U, Bental T, Sagie A, Shapira Y, et al. Usefulness of the CHA2DS2-VASc score to predict outcome in patients who underwent transcatheter aortic valve implantation. Am J Cardiol. 2018;121:241-8.

2. Melgaard L, Gorst-Rasmussen A, Lane DA, Rasmussen LH, Larsen TB, Lip GYH Assessment of the CHA2DS2-VASc score in predicting ischemic stroke, thromboembolism, and death in patients with heart failure with and without atrial fibrillation. JAMA. 2015;314:1030-8. 
3. Kiviniemi T, Lehto J, Nissinen M, Nieminen T, Hartikainen J, Malmberg M, et al. Performance of CHA2DS2-VASc score for stroke prediction after surgical aortic valve replacement. J Thorac Cardiovasc Surg. 2019;157:896-904.

4. Fine JP, Gray RJ. A proportional hazards model for the subdistribution of a competing risk. J Am Stat Assoc. 1999;94:496-509.
5. Camm AJ, Kirchhof P, Lip GY, Schotten U, Savelieva I, Ernst S, et al; European Heart Rhythm Association; European Association for Cardio-Thoracic Surgery. Guidelines for the management of atrial fibrillation: task force for the management of atrial fibrillation of the European Society of Cardiology (ESC). Eur Heart J. 2010;31:2369-429. 